\title{
Dış Merkezde ve Hastanemizde Sürfaktan Uygulanan Hastaların Karşılaştırılması
}

\author{
A Comparison of Patients Who Had Given Surfactant Therapy \\ in the Out-Center with Our Hospital
}

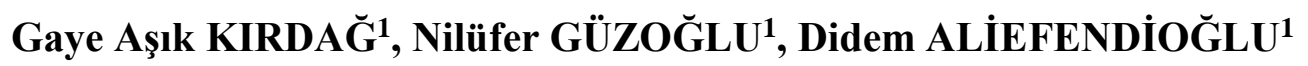

${ }^{1}$ Kırıkkale Üniversitesi Tıp Fakültesi, Pediatri A.D., KIRIKKALE

\begin{abstract}
ÖZET
Erken sürfaktan tedavisi, sürfaktan eksikliği olan prematüre bebeklerde ventilasyonu destekleyerek hayat kurtarıcı olabildiği gibi, respiratuvar distres bulguları olan ancak Respiratuar Distres Sendromu olmayan bebeklere uygulandığında, gereksiz entübasyon ve mekanik ventilasyon tedavisi ile sonuçlanabilmektedir. $\mathrm{Bu}$ çalışmanın amacı ünitemize sevk edilen hastalar ile hastanemizdeki sürfaktan uygulamalarının karşılaştırılmasıdır.

Kırıkkale Üniversitesi Tıp Fakültesi Yenidoğan yoğun bakım ünitesinde son bir yıl içinde Respiratuar Distres Sendromu tanısıyla sürfaktan uygulanan bebekler geriye yönelik olarak incelendi. Hastalar sürfaktan tedavisinin uygulandığı merkeze göre iki gruba ayrıldı. Sürfaktan uygulanması dış merkezde yapılanlar 1. Grubu, kliniğimizde sürfaktan uygulananlar ise Grup 2'yi oluşturdu. Her iki grup gebelik haftası, doğum ağırlığı, antenatal steroid, cinsiyet, APGAR skoru ve sürfaktan verilme endikasyonları açısından karşılaştırıldı.

Çalışmamıza birinci grupta 12, ikinci grupta 49 hasta olmak üzere toplam 61 hasta dahil edildi. Grup 1'in ortanca gebelik haftası ve doğum ağırlığı, Grup 2'den yüksek bulundu $(\mathrm{p}<0.05)$. Sevk edilen hastalardan sadece 4'ünde (4/12) klinik ve radyolojik bulgularla Respiratuar Distres Sendromu düşünüldü ve hastaların tamamı kliniğimize başvuruda ekstübe edilerek izleme alındı.

Sürfaktan uygulaması, protokoller 1şığında yapılması gereksiz tedavi ve entübasyonu önleyebilir. Bu çalışma vaka sayısının az olması nedeni ile tüm toplumu yansıtmamakla birlikte, daha fazla veri ile yapılacak çalışmalar için yol gösterici olabilir.
\end{abstract}

Anahtar Kelimeler: Yenidoğan, sürfaktan, Respiratuar Distres Sendromu

\begin{abstract}
Early exogenous surfactant therapy can save lives by improving ventilation in newborn who have surfactant deficiency. However, it can expose a newborn who will not develop Respiratory Distress Syndrome to intubation, mechanical ventilation, and expose the newborn to a drug that may not be necessary. The aim of this study is to compare surfactant therapy practice between patients who were given surfactant at our hospital and out center.

All neonates who received surfactant therapy because of Respiratory Distress Syndrome over one year period were reviewed retrospectively. Patients were divided into two groups according to where given surfactant. Group 1: Patients who were given surfactant at out center; Group 2: Patients who were given surfactant at our hospital. Gestational age, birth weight, antenatal steroids, sex, APGAR scores and indications of surfactant replacement therapy were compared between groups.

Among 61 infants enrolled in the study, 12 were given surfactant by out-center and 49 were given by the in-center. The median gestational age and the median birthweight were both significantly higher in the Group 2 compared with the in-center $(p<0.05)$. Four infants $(4 / 12)$ were given surfactant for rescue treatment in out-center group. These infants were extubated on arrival of our hospital.

If surfactant should be implemented according to the protocol, unnecessary treatment and intubation can be prevented. This study doesn't provide population based information. However, it can provide information for planning research, allocating resources, designing health.
\end{abstract}

Keywords: Newborn, surfactant, Respiratory Distress Syndrome
KÜ Tıp Fak Derg 2015; 17(2): 16-20

Geliş Tarihi / Received: 28.04.2014

Kabul Tarihi / Accepted: 28.05.2014
Yazışma Adresi / Correspondence: Gaye Aşık KIRDAĞ

Dicle Üniversitesi Tip Fak Dermatoloji AD, DIYYARBAKIR

E-posta: gaye.asik@yahoo.com.tr Tel: 05303156156 


\section{GíRíş}

Respiratuvar distres sendromu (RDS) prematüre yenidoğanlarda en sık karşılaşılan solunum sıkıntısı nedenidir. RDS sürfaktanın eksikliğinden, fonksiyonel bozukluğundan veya inaktivasyonundan kaynaklanmaktadır (1). Solunum yollarındaki yüzey gerilimini düzenleyen bir lipid-protein kompleksi olan sürfaktan; 20-24. haftalarda tip 2 pnömositlerde sentezlendikten sonra, 24. haftadan itibaren lamellar cisimlerde depolanır ve 28-30. haftalardan sonra salgılamaya başlar ve 35-36. gestasyonel haftada yeterli düzeye ulaşır (2). Bu nedenle gebelik haftasının azalmasıyla birlikte RDS sıklığı artmaktadır.

Sürfaktanla ilgili ilk düşünceler, 1959 y1lında Avery ve Mead'ın RDS'li prematürelerin akciğerlerinde yüzey aktif maddelerin eksik olduğunu bildirmeleriyle başlamıştır (6). 1972'de Enhorning ve ark. (7) tarafından RDS'deki esas sorunun sürfaktan eksikliği olduğu gösterilmiş ve doğal sürfaktanla yenidoğanda ilk tedavi 1980 yılında Fujiwara ve arkadaşları tarafindan uygulanmıştır (8). Ülkemizde de 1990'lı yılların başından itibaren özellikle RDS ve mekonyum aspirasyon sendromu tedavisinde sürfaktan uygulanmaya başlanmıştır. Günümüzde sürfaktan tedavisi genetik eksiklik, pnömoni, akut akciğer hasarı, pulmoner kanama gibi birçok klinik durumda başarıyla kullanılmaktadır (9). Bunun yanında gereksiz entübasyon, pulmoner kanama gibi riskleri ve maliyeti göz önünde bulundurularak endikasyon varlığında kullanım konusunda dikkatli olunmalıdır.

$\mathrm{Bu}$ çalışmada ünitemize sevk edilen hastalarda sürfaktan uygulamalarının karşıllaştırılması amaçlanmıştır. Ayrıca sürfaktan kullanım endikasyonları ve gereksiz sürfaktan kullanımından kaçınmanın önemi tartışılmak istenmiştir.

\section{GEREÇ VE YÖNTEM}

$\mathrm{Bu}$ çalışmada Kırıkkale Üniversitesi Tıp Fakültesi Yenidoğan Yoğun Bakım Ünitesinde Ocak 2014Aralık 2014 tarihleri arasında yatarak tedavi edilen bebekler geriye dönük olarak incelendi. Çalışmaya en az bir kez sürfaktan alan bebekler alındı. Nosokomial pnömoni nedeni ile sekonder sürfaktan eksikliği düşünülen bebekler çalışma dışı bırakıldı. Hastalar başka bir merkezde sürfaktan alıp tarafımıza sevk edilenler (Grup 1) ve ünitemizde sürfaktan alanlar (Grup 2) olmak üzere 2 gruba ayrıldı. Dosya kayıtlarından maternal komplikasyonlar, antenatal steroid uygulaması, APGAR skoru, sürfaktan verilme endikasyonları yanı sıra hastaların cinsiyeti, doğum ağırlığı, doğum şekli, gebelik yaşı, fizik muayene bulguları, mekanik ventilasyon gereksinimi ile süresi, hastanede yatış süresi ve mortalite verileri kaydedildi. İstatistiksel analizlerde, SPSS istatistik paket programı (17.0, IL, USA) kullanıldı. Tanımlayıcı veriler 'ortalama \pm standart sapma' olarak verildi. İstatistiksel karşılaştırmalarda 0.05 'in altındaki p değerleri anlamlı kabul edildi.

\section{BULGULAR}

Ocak 2014-Aralık 2014 tarihleri arasında merkezimizde 49, dış merkezde 12 hastaya sürfaktan uygulanmış idi. Sürfaktan alan hastaların gestasyonel yaşları 23-41 hafta ve doğum ağırlıkları 370 - 4020 gr arasında bulundu. Her iki grup karşılaştırıldığında maternal komplikasyonlar, antenatal steroid uygulamas1, sezaryen ile doğum, erkek cinsiyet ve APGAR skoru açısından gruplar arasında fark bulunmad1 ( $p>0.05)$. Grup1'in ortanca gebelik yaşı 33 hafta (25-38) ve ortanca doğum ağırlığ 2195 gr (5803400) olup Grup 2' ye göre istatiksel anlamlı olarak daha yüksekti (Ortanca gebelik yaşı 28 hafta (23-41); ortanca doğum ağırlığı 1060 gr $(370-4020))(\mathrm{p}<0.05)$ (Tablo 1). Sevk edilen hastalardan sadece 4'ünde (4/12) klinik ve radyolojik bulgular RDS ile uyumlu bulundu ve hastaların tamamı kliniğimize başvuruda ekstübe edilerek izleme alındı. $\mathrm{Bu}$ hastaların izlemlerinde reentübasyon ve sürfaktan gereksinimleri olmad1. Morbidite ve mortaliteler arasında fark olmaması grupların gebelik yaşı ve doğum ağırlıkları açısından karşılaştırılabilir olmaması nedeniyle dikkate alınmadi. 
Tablo 1. Grupların maternal ve demografik özellikler açısından karşılaştırılması

\begin{tabular}{llll}
\hline & Grup 1 (n=12) & Grup 2(n=49) & $\mathrm{p}$ \\
\hline Preeklampsi (n, \%) & $1(7)$ & $11(23)$ & 0,51 \\
Gestasyonel diyabet (n, \%) & $1(8)$ & $4(8)$ & 0,67 \\
Sezaryen ile doğum (n, \%) & $9(75)$ & $38(78)$ & 0,56 \\
Erkek cinsiyet (n, \%) & $7(49)$ & $24(58)$ & 0,39 \\
Gebelik haftası $\quad$ ortanca (aralık) & $33(25-38)$ & $28(23-41)$ & 0,007 \\
Doğum ağırlığ (gr) $\quad$ ortanca (aralık) & $2195(580-3400)$ & $1060(370-4020)$ & 0,014 \\
\hline
\end{tabular}

\section{TARTIŞMA}

Ülkemizde bir yılda doğan yaklaşık 1,5 milyon bebeğin 17000'i ilk bir ay içinde ölmekte ve ölüm nedenlerinin $\% 25$ ' ini prematüre doğum ve RDS oluşturmaktadır (5). Ancak RDS dişında da özellikle geç pretermlerde yaş akciğer sık görülen bir solunum sıkıntısı nedenidir ve klinik bulguları ile RDS'ye benzeyebilir. Ayrıca grup B streptokok pnömonisi klinik ve radyolojik bulguları ile RDS'den ayırt edilemeyebilir. Ayırıcı tanıda siyanotik konjenital kalp hastalıkları, persistan fetal dolaşım, aspirasyon sendromları, spontan pnömotoraks, plevral effüzyon, diyafragma evantrasyonu ve konjenital anomaliler de gözönüne alınmalıdır (2). Ancak bu tabloların hiçbirinin tedavisinde sürfaktanın yeri yoktur. Sürfaktan son 20 yılda RDS'nin standart tedavisi olmasına rağmen, kullanım şekli ve dozu konusunda halen fikir ayrılıkları vardır $(1,10,11)$. Son yayınlanan Avrupa Uzlaşı bildirisinde sürfaktan kullanım endikasyonları kısıtlanmış olup, non-invaziv ventilasyon yöntemleri ön plana çıkmıştır. Erken sürfaktan tedavisi, respiratuvar distres bulguları olan ancak RDS olmayan bebeklere uygulandığında, gereksiz entübasyon ve mekanik ventilasyon tedavisi ve ona bağl1 komplikasyonlara yol açmaktadır. Antenatal steroid kullanımı ve doğum salonundan itibaren CPAP (Continuous Positive Airway Pressure; Devamlı Pozitif Basınçlı Ventilasyon) başlanması ile bu uygulama yerini, erken CPAP ve selektif sürfaktan uygulamasına, yani daha az invaziv yöntemlere bırakmıştır. Bizim kliniğimizde de ileri derecede preterm bebeklere doğum salonundan itibaren noninvaziv mekanik ventilasyon tedavisi uygulanmaktadır.

RDS gelişme riski olan tüm yenidoğanlara koruyucu sürfaktan uygulamasının erken kurtarma tedavisi ile karşılaştırıldığı daha önceki çalışmalarda, koruyucu uygulamanın hava kaçağı sendromları ve ölüm oranında azalma sağladığı gösterilmiştir (16,21). Ancak, yakın dönemde yayınlanan çalışmalarda doğum öncesi steroidlerin daha fazla kullanılmasıyla, doğum sonrası CPAP ile stabilleştirme sonuçlarının daha önceki çalışmalardan farklı olduğu bildirilmiştir. Doğum sonrası erken CPAP ile stabilleştirme ve sonrasında sadece entübasyon gerektiren olgulara selektif sürfaktan uygulamasıyla, kronik akciğer hastalığı ve ölüm riskinde azalma olduğu saptanmıştır (22). Sandri ve ark. (23) çalışmalarında kendiliğinden solunumu olan bu olgularda ilk beş günde mekanik ventilasyon gereksinimi, 28. günde ve postmenstrüel 36. haftada erken doğum hastalıkları ve ölüm açısından fark saptanmamıştır. Bu nedenle çalışmalarından elde edilen bu bulgular, doğum odasında burundan CPAP ile başlanıp RDS bulguları ortaya çıktığında sürfaktan yaprlabileceğini göstermiştir (24). Sürfaktan tedavisinin yan etkilerine bakıldığında, akut dönemde uygulama sırasında geçici olarak bradikardi, hipoksemi 
ve endotrakeal tüpte blokaj gelişebilmektedir. Ayrıca statik pulmoner kompliyansta dramatik değişikliklere bağlı olarak barotravma meydana gelebilmektedir. Sürfaktan tedavisi sonrası akciğer kanama sıklığının artabileceği bildirilmektedir (12). Çalışmamızın sonuçları sürfaktanın gereksiz kullanımı ile hastaya zarar verme potansiyeli ve maliyet artışının sorgulanması gerektiğini düşündürmektedir.

Sonuç olarak maliyetli ve invaziv bir yöntem olması nedeniyle gereksiz sürfaktan kullanımından kaçınılmalı, kar ve zarar analizi iyi yapılmalıdır. Her invaziv yöntem gibi entübasyona bağlı komlikasyonlar da akılda tutulmalıdır. Sürfaktan tedavisinin RDS tablosundaki sonuçları yüz güldürücüdür. Ancak sürfaktanın kullanım endikasyonları iyi bilinmeli, bebeğin kliniği iyi değerlendirilmelidir. $\mathrm{Bu}$ çalışma vaka sayısının az olması nedeni ile tüm toplumu yansıtmamakla birlikte, daha fazla veri ile yapılacak çalışmalarda yol gösterici olabilir.

\section{KAYNAKLAR}

1. Rodriguez RJ. Management of respiratory distress syndrome: an update. Respir Care. 2003; 48(3): 279-86.

2. Korkmaz A. Respiratuar distres sendromu ve komplikasyonları Sağlık Bakanlığı Kurs Kitabı. 2010: 73-86.

3. Valls i Soler A, Pijoán JI, Pallás Alonso CR, de la Cruz Bértolo J; Comité Directivo de EuroNeoStat. EuroNeoStat. A European information system on the outcomes of care for extremely low birthweight infants. An Pediatr (Barc). 2006; 65(1): 1-4.

4. Costakos D, Allen D, Krauss A, Ruiz N, Fluhr K, Stouvenel A, et al. Surfactant therapy prior to the interhospital transport of preterm infants. Am J Perinatol. 1996; 13(5): 309-16.

5. Neonatal resusitasyon programı 2011. T.C. Sağlık Bakanlığı Ana Çocuk Sağlığı ve Aile Planlaması Genel Müdürlüğü.
6. Avery ME, Mead J. Surface properties in relation to atelectasis and hyaline membrane disease. Am J Dis Child. 1959; 97: 517-23.

7. Enhörning G, Robertson B. Lung expansion in the premature rabbit fetus after tracheal deposition of surfactant. Pediatrics. 1972; 50: 58-66.

8. Fujiwara T, Maeta H, Chida S, Morita T, Watabe $\mathrm{Y}$, Abe T. Artificial surfactant therapy in hyalinemembrane disease. Lancet. 1980; 12: 55-59.

9. Kültürsay N, Uygur Ö, Yalaz M. Yenidoğan döneminde sürfaktan kullanımı-bilinenler, halen araştırılanlar, araştırılması gerekenler. Türk Ped Arş. 2014; 49: 1-12.

10. Schwartz RM, Luby AM, Scanlon JW, Kellogg RJ. Effect of surfactant on morbidity, mortality, and resource use in newborn infants weighing 500 to 1500 g. N Engl J Med. 1994; 330: 1476-80.

11. Suresh GK, Soll RF. Exogenous surfactant therapy in newborn infants. Ann Acad Med Singapore. 2003; 32: 335-45.

12. Speer CP. Neonatal respiratory distress syndrome: An inflammatory disease? Neonatology. 2011; 99: 316-9.

13. Sweet DG, Carnielli V, Greisen G, Hallman M, Ozek E, Plavka R, Saugstad OD, Simeoni U, Speer $\mathrm{CP}$, Halliday HL; European Association of Perinatal Medicine. European consensus guidelines on the management of neonatal respiratory distress syndrome in preterm infants-2010 update. European Association of Perinatal Medicine. Neonatology. 2010; 97(4): 402-17.

14. Kendig JW, Ryan RM, Sinkin RA, Maniscalco WM, Notter RH, Guillet R, et al. Comparison of two strategies for surfactant prophylaxis in very premature infants: a multicenter randomized trial. Pediatrics. 1998; 101: 1006-12.

15. Stevens TP, Harrington EW, Blennow M, Soll RF. Early surfactant administration with brief ventilation vs. selective surfactant and continued 
mechanical ventilation for preterm infants with or at risk for respiratory distress syndrome. Cochrane Database Syst Rev. 2007; 4:CD003063.

16. Soll R, Ozek E. Prophylactic protein free synthetic surfactant for preventing morbidity and mortality in preterm infants. Cochrane Database Syst Rev. 2010; 1:CD001079.

17. Morley CJ, Davis PG, Doyle LW, Brion LP, Hascoet JM, Carlin JB; COIN Trial Investigators. Nasal CPAP or Intubation at birth for very preterm infants. N Engl J Med. 2008; 358(14):1529.

18. Finer NN, Carlo WA, Walsh MC, Rich W, Gantz MG, Laptook AR, Yoder BA, Faix RG, Das A, Poole WK, Donovan EF, Newman NS, Ambalavanan N, Frantz ID, Buchter S, Sánchez PJ, Kennedy KA, Laroia N, Poindexter BB, Cotten CM, Van Meurs KP, Duara S, Narendran V, Sood BG, O'Shea TM, Bell EF, Bhandari V, Watterberg KL, Higgins RD. Early CPAP versus surfactant in extremely preterm infants. N Engl J Med. 2010; 362(23): 1970-9.

19. Kandraju H, Murki S, Subramanian S, Gaddam P, Deorari A, Kumar P. Early routine versus late selective surfactant in preterm neonates with respiratory distress syndrome on nasal continuous positive airway pressure: A randomized controlled trial. Neonatology. 2012; 103: 148-54.
20. Dunn MS $^{1}$, Kaempf J, de Klerk A, de Klerk R, Reilly M, Howard D, Ferrelli K, O'Conor J, Soll RF; Vermont Oxford Network DRM Study Group. Randomized trial comparing 3 approaches to the initial respiratory management of preterm neonates. Pediatrics 2011; 128(5): 1069-76.

21. Soll RF. Multiple versus single dose natural surfactant extract for severe neonatal respiratory distress syndrome. Cochrane Database Syst Rev. 2000; (2): CD000141.

22. Rojas-Reyes MX, Morley CJ, Soll R. Prophylactic versus selective use of surfactant in preventing morbidity and mortality in preterm infants (Review). Cochrane Database Syst Rev. 2012; 14 : CD000510.

23. Sandri F, Plavka R, Ancora G, Simeoni U, Stranak Z, Martinelli S, Mosca F, Nona J, Thomson M, Verder H, Fabbri L, Halliday H; CURPAP Study Group. Prophylactic or early selective surfactant combined with nCPAP in very preterm infants. Pediatrics. 2010; 125(6): 1402-9.

24. Bohlin K. RDS-CPAP or surfactant or both. Acta Pediatrica. 2012; 101: 24-8. 